ORIGINAL ARTICLE

\title{
Influence of ultra-endurance exercise on immunoglobulin isotypes and subclasses
}

\author{
A J McKune, L L Smith, S J Semple, A A Wadee
}

Br J Sports Med 2005;39:665-670. doi: 10.1136/bjsm.2004.017194

See end of article for authors' affiliations

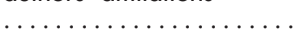

Correspondence to: Mr McKune, Department of Sport and Physical Rehabilitation Sciences, Tshwane University of Technology, Pretoria, South Africa; mckuneaj@ tut.ac.za

Accepted 30 January 2005
Background: Strenuous exercise is associated with tissue damage. This activates the innate immune system and local inflammation. Interaction between innate and adaptive immunity is essential for maintaining health, suggesting that the adaptive immune system may also be altered by exercise.

Objectives: To determine exercise induced changes in the adaptive immune system by measuring the immunoglobulin isotype and subclass response to an ultra-marathon.

Methods: Venepuncture was performed on 11 experienced volunteers (six men, five women; mean (SD) age 43 (9.8) years) 24 hours before the projected finishing time and immediately after and 3,24, and 72 hours after an ultra-marathon $(90 \mathrm{~km})$. Serum was stored at $-80^{\circ} \mathrm{C}$. $\lg M, \lg D, \lg A, \lg G, \lg \mathrm{G} 1,2,3$, and 4 , and total $\lg E$ were measured.

Results: The following immunoglobulins were significantly $(p \leqslant 0.05)$ altered after the race: $\lg D$, immediately $(-51 \%)$ and 24 hours $(-41 \%)$ after; $\lg M 24$ hours after $(-23 \%)$; total lgG immediately after $(+12 \%)$. There were no reports of symptoms of upper respiratory tract infections after the ultra-marathon. Conclusions: In experienced ultra-endurance runners, alterations in immunoglobulin concentrations after a race suggest an enhanced immune response, including isotype switching, interactions with the innate immune system, and a secondary antibody response. These alterations may have a role in the maintenance of subject health after an ultra-marathon.
1 $\mathrm{n}$ the last two decades, it has been suggested that acute, intense bouts of long duration exercise (more than two hours), such as marathon or ultra-marathon, increases the risk of upper respiratory tract infection (URTI). ${ }^{12}$ This increased risk of infection (viral or bacterial) suggests a suppressed or altered immunity. ${ }^{3}$ To elucidate what exercise induced changes occur, researchers have examined different aspects of immune function, such as macrophage activation, ${ }^{5}$ natural killer cell number and activation, ${ }^{6}$ lymphocyte proliferation, ${ }^{7}$ and cytokine production. $^{8}$ Recently, it has been suggested that intense long duration exercise may initiate the upregulation of a Th2 lymphocyte response which, by definition, would suppress cell mediated immunity and thus put certain people at risk of developing URTI. ${ }^{3}$

Much of the research focus has emphasised the significantly increased risk of URTI after strenuous exercise. ${ }^{12}$ However, it should be noted that most people involved in such competition do not develop URTI. Unquestionably, many aspects of the immune/inflammatory system contribute to health maintenance, especially when the body is placed under physical stress such as during an ultramarathon.

Circulating antibodies/immunoglobulins are generally associated with the humoral arm of adaptive immunity. ${ }^{9}$ During a primary antibody response, $\mathrm{T}$ cells and antigen activate naive $\mathrm{B}$ cells, which then differentiate into short lived plasma cells, long lived plasma cells (three to four months in mice), or memory B cells. ${ }^{10}$ The short lived plasma cells are produced first and provide a rapid antigen specific defence and initiation of the primary antibody response. This involves an early rise in antibodies of the antigen specific IgM class (isotype), followed by affinity maturation, isotype switching, and a rise in antigen specific IgG, IgA, and/or IgE antibodies. ${ }^{11}$ This response requires up to 10 days to become fully activated. ${ }^{12}$ However, during subsequent reexposure to antigen, a rapid secondary antibody response is initiated by the long lived plasma cells. ${ }^{10}$ These provide an immediate high affinity antibody response to antigen in the circulation without the need for activation of memory B cells, which is a slower process.

The exercise related studies that have examined changes in immunoglobulin responses are not in agreement. Some studies have shown no change, ${ }^{13}$ some have shown increases, ${ }^{14-16}$ and others have shown depressed immunoglobulin response or failed to measure all the immunoglobulin isotypes and subclasses. ${ }^{16-18}$ Therefore the aim of this study was to determine alterations in serum concentrations of immunoglobulin isotypes and subclasses after an ultramarathon.

\section{METHODS \\ Subjects}

Initially 25 experienced runners from local running clubs, who had entered the $90 \mathrm{~km}$ Comrades Ultra-Marathon, South Africa in 2002, volunteered to participate in this study. These runners did not smoke or have asthma, allergic rhinitis, or respiratory disease. There was a 56\% drop out rate from the study because of failure to complete the race (10) or failure to comply with the study protocol (4). Therefore the study presents the immunoglobulin response of 11 runners (six men, five women). The protocol was approved by the institution's ethics committee, and written informed consent was obtained from each subject.

\section{Study design}

The subjects reported to the exercise testing laboratory two weeks before the race where they completed questionnaires on their health history, training schedule (distance run in the preceding six months), and ultra-marathon experience. After completion of the questionnaires, body composition and cardiorespiratory fitness were determined.

Abbreviations: URTI, upper respiratory tract infection; $\dot{V}_{2} \operatorname{MAX}$, maximal oxygen uptake 


\section{Measurement of body composition}

Height and weight were recorded using a calibrated medical height gauge and balance scale (Detecto, Webb City, Missouri, USA). A Harpenden skinfold calliper was used for skinfold measurements (seven sites) to assess body composition using the Drinkwater-Ross method. ${ }^{19}$

\section{Measurement of maximal oxygen uptake (Vัo ${ }_{2} \mathrm{MAX}$ ) and heart rate}

Subjects were instructed to abstain from high intensity or long duration training sessions on the day before being tested. They were also instructed to eat a light meal three hours before the $\dot{\mathrm{V}}_{2} \mathrm{MAX}$ testing. The test was performed on a Quinton 90 treadmill (Quinton Instrument Co, Seattle, Washington, USA). Continuous respiratory measurements were recorded with the MedGraphics CardiO ${ }_{2}$ combined $\dot{\mathrm{V}}_{2} /$ ECG exercise system (Medical Graphics Corporation, Chicago, Illinois, USA). Heart rate response was monitored using a Polar Heart Rate Monitor (Kempele, Finland). The test began at $8 \mathrm{~km} / \mathrm{h}$ on a $3 \%$ incline, for five minutes. Thereafter, speed and gradient were increased at $1 \mathrm{~km} / \mathrm{h}$ and $1 \%$ respectively every minute. From $12 \mathrm{~km} / \mathrm{h}$, only the gradient was increased by $1 \%$ per minute until exhaustion. ${ }^{20}$ Standard criteria were used to ensure attainment of $\dot{\mathrm{V}}_{2} \mathrm{MAX}^{21}$

\section{URTI}

Twenty four hours before the projected finishing time, the runners completed a questionnaire on their state of health during the two weeks leading up to the race. For two weeks after completion of the race, the subjects completed a validated, daily questionnaire on the severity and duration of URTI. The questionnaire included a scale, which assessed the severity and duration of self reported URTI such as a running nose, sneezing, sore throat, and cough. ${ }^{22}$

\section{Blood sampling}

Venous blood samples ( $15 \mathrm{ml}$ ) were collected 24 hours before the projected finishing time, and then within 10 minutes of finishing the ultra-marathon and 3, 24, and 72 hours later. A $5 \mathrm{ml}$ sample of blood was collected in a glass Vacutainer tube containing the anticoagulant tripotassium ethylenediaminetetra-acetic acid ( $\mathrm{K}_{3}$-EDTA) and used to determine full blood counts. A $10 \mathrm{ml}$ sample was collected in a serum separator tube, which was kept at room temperature for 30 minutes. This tube was then centrifuged for 10 minutes, and the serum divided into $0.5 \mathrm{ml}$ aliquots and stored at $-80^{\circ} \mathrm{C}$ until analysis.

\section{Haematological adjustments}

Full blood counts were performed on $\mathrm{K}_{3}$-EDTA treated specimens using standard haematological procedures on an automated STKS model (Coulter Electronics Inc, Hialeah, Florida, USA). Changes in plasma volume were determined and corrected for from haemoglobin concentrations and packed cell volumes recorded before and after the race using the method of Dill and Costill. ${ }^{23}$

\begin{tabular}{|ll|}
\hline \multicolumn{2}{|l|}{ Table 1 Subject characteristics } \\
\hline Variable & Mean (SD) \\
\hline Age (years) & $43(10)$ \\
Height $(\mathrm{cm})$ & $170(10)$ \\
Weight $(\mathrm{kg})$ & $64(13)$ \\
Body fat $(\%)$ & $14(3)$ \\
Vo ${ }_{2}$ MAX $(\mathrm{ml} / \mathrm{kg} / \mathrm{min})$ & $57.5(6)$ \\
Heart rate maximum (beats $/ \mathrm{min})$ & $172(15)$ \\
Weekly training distance (km/week) & $58(17)$ \\
Race time (hours) & $9.45(1.1)$ \\
\hline & \\
\hline
\end{tabular}

\section{Determination of total immunoglobulins and IgG subclasses}

The total amount of $\operatorname{Ig}$ M, IgD, IgA, IgG, and IgG subclasses was quantified by incubation with appropriate antisera (anti-human IgM, IgD, IgA, IgG and IgG1, IgG2, IgG3 and IgG4; Behring, Frankfurt, Germany). The amount of complex (immunoglobulin-anti-immunoglobulin) formed was measured by light scatter, using laser nephelometry (Behring), and the amount of antibody present quantified by comparison with standards of known concentration.

Total serum IgE was determined with the Alastat Microplate Total IgE kit (Diagnostic Products, Los Angeles, California, USA) according to the manufacturer's instructions and by comparisons with a known range of standard IgE concentrations.

\section{Statistical analysis}

Data were analysed using commercial software (SAS Institute, Cary, North Carolina, USA) using a repeated measures analysis of variance, and comparing variables with baseline values. Results are expressed as mean (SE). The level of significance was set at $\mathrm{p} \leqslant 0.05$.

\section{RESULTS}

\section{Subject characteristics}

Table 1 gives basic information on the subjects. They were all experienced ultra-marathon runners having completed an average of four ultra-marathons. The mean distance covered in training in preparation for the ultra-marathon was $1377.3 \mathrm{~km}$ (January to June). The mean (SE) time taken to complete the race $(9.45$ (1.1) hours) indicates that the athletes were not elite. The cut off time for the race is 11 hours, with the top 10 runners usually completing the $90 \mathrm{~km}$ in less than six hours. There were no reports of symptoms of URTI in the two weeks before or after the ultramarathon.

\section{Serological variables}

All serum immunoglobulin concentrations before and after the race were within clinically normal reference ranges. Statistical analyses of the different immunoglobulins are discussed individually.

\section{$\lg D$}

Contrast testing revealed that $\operatorname{IgD}$ concentration had significantly decreased immediately after $(-51 \%, \mathrm{p}=0.04)$ and 24 hours after $(-41 \%, p=0.04)$ the race but not three hours after $(\mathrm{p}=0.15)$. By 72 hours, IgD concentrations had returned to baseline (fig 1).

\section{$\lg M$}

Contrast testing suggested a decrease immediately $(\mathrm{p}=$ $0.76)$ and three hours ( $p=0.36)$ after the race, although this was not significant. However, by 24 hours, IgM was significantly decreased $(-23 \%, \mathrm{p}=0.04)$ compared with concentrations before the race. IgM remained lower at 72 hours $(-22 \%)$, although this value was not significant $(\mathrm{p}=0.09)($ fig 1$)$.

\section{$\lg \mathbf{G}$ (total)}

A significant time effect was found for $\operatorname{IgG}(p=0.02)$. Contrast testing revealed that IgG was significantly raised immediately after the race $(+12 \%, p=0.05)$; at three hours there was still a $5 \%$ increase, but this was not significant $(\mathrm{p}=0.07)$. At 24 and 72 hours, concentrations had returned to baseline (table 2). 

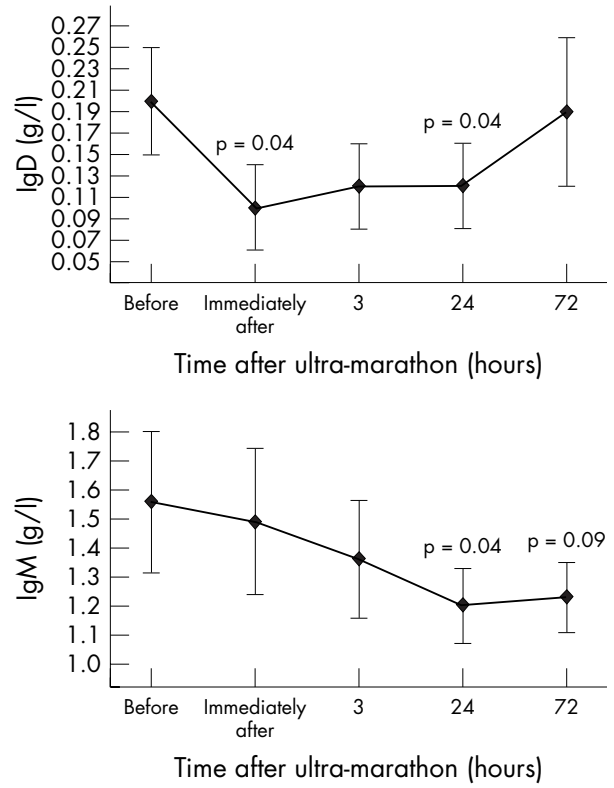

Figure 1 Immunoglobulin $D(\lg D)$ and immunoglobulin $M(\lg M)$ concentration immediately after the ultra-marathon and up to three days later. Values are mean (SE). $p \leqslant 0.05$, significantly different from the before time point.

\section{$\lg G$ isotypes $(\lg G 1,2,3,4)$}

$\lg G 1$

Contrast testing revealed that IgGl was increased immediately $(+12 \%)$ and three hours $(+4.5 \%)$ after the race, although these values were not significant $(p=0.09)$. At 24 and 72 hours, concentrations had returned to baseline (fig 2).

\section{$\lg G 2$}

Contrast testing showed a 15\% increase in IgG2 immediately after the race, but this was not significant $(\mathrm{p}=0.09)$. By 24 and 72 hours, IgG2 concentrations had returned to baseline (fig 2).

\section{$\lg G 3$}

Contrast testing suggested a $3 \%$ increase immediately after the race, but this was not significant $(p=0.63)$. There appeared to be a decrease at 24 and 72 hours but this was also not significant (fig 2).

\section{$\lg G 4$}

Contrast testing revealed that immediately after the race, there was a $16 \%$ increase in IgG4 but this was not significant $(p=0.07)$. By three hours the concentration had returned to baseline (fig 2).

\section{$\lg E$}

Immediately after the race, there was a $12 \%$ increase in $\operatorname{IgE}$ concentration but this was not significant $(p=0.52)$. IgE remained at this concentration at 24 hours $(+12 \%, p=0.24)$ and 72 hours $(+12 \%, p=0.5)$. It should be noted that there was a large amount of individual variability, with the standard error being almost equal to or greater than the mean (table 2).

\section{$\lg A$}

Immediately after the race, there was a 10\% increase in IgA, but this was not significant $(\mathrm{p}=0.65)$. This was followed by a $6 \%$ decrease at three hours, a $10 \%$ decrease at 24 hours, and a $6 \%$ decrease at 72 hours. These values were not significant $(\mathrm{p}=0.6)($ table 2$)$.

\section{DISCUSSION}

The focus of many previous studies has been to identify changes in serum or salivary immunoglobulin concentrations after an acute bout of strenuous exercise, in an attempt to determine alterations that may be associated with increased risk of URTI. ${ }^{14}{ }^{24}$ However, in this study, as none of the participants experienced a URTI in the two weeks after the ultra-marathon, the discussion will attempt to elucidate changes in immunoglobulin concentration that possibly assist in the maintenance of health ${ }^{25}$ after an acute bout of stressful exercise.

An interesting finding in this study was the significant $12 \%$ increase in total serum IgG immediately after the race. This increase was accompanied by a decrease in $\operatorname{IgM}$ and IgD, with both immunoglobulins being significantly reduced at 24 hours. Generally in exercise immunology, an increase in immunoglobulin concentration has usually been interpreted to represent enhanced immunity, and a decrease is usually interpreted as immunosuppression. ${ }^{24}$ We suggest that this is overly simplistic and that alterations in different immunoglobulins may reflect isotype switching and interaction with the innate immune system.

With regard to changes in IgG, it appears that research is conflicting, ${ }^{14}{ }^{24}$ with few studies measuring this isotype after ultra-endurance exercise. Alterations induced by shorter acute bouts of exercise and training have been reported. Poortmans $^{26}$ found a significant $12 \%$ increase in serum IgG immediately after a progressive cycle ergometer test to fatigue (mean duration 21 minutes). However, Nieman and Nehlsen-Cannarella ${ }^{14}$ found that IgG decreased during recovery after a three hour run at marathon pace, reaching its lowest point at 1.5 hours $(-7.6 \%)$ and rising to baseline concentration 21 hours after exercise. Similarly to the present findings, Poortmans and Haralambie ${ }^{27}$ reported a significant $7 \%$ increase in $\operatorname{IgG}$ immediately after a $100 \mathrm{~km}$ race. However, Israel et $a^{28}$ reported that 25 hours after a $75 \mathrm{~km}$ run at high intensity, IgG was decreased by $22 \%$. Training induced decreases in IgG have been reported. Mashiko et al ${ }^{18}$ found a significant decrease in IgG $(-8 \%)$ after a 20 day rugby training camp, training two hours a day, six days a week. Recently, Petibois et al ${ }^{16}$ monitored immunoglobulin alterations over 12 months of rowing training, and, like the present study, found that IgGl, IgG2 and IgG4 increased as the result of exercise. However, they found that IgG3 decreased up to the 18th week of training and remained low from that point.

Table 2 Serum immunoglobulin concentrations before and after an ultra-marathon race

\begin{tabular}{llllll}
\hline Immunoglobulin & $\mathbf{2 4} \mathbf{h}$ before & $\begin{array}{l}\text { Immediately } \\
\text { affer }\end{array}$ & $\mathbf{3} \mathbf{h}$ after & $\mathbf{2 4} \mathbf{~}$ after & $\mathbf{7 2} \mathbf{~}$ after \\
\hline $\operatorname{lgA}(\mathbf{g} / \mathrm{l})$ & $2.182(0.27)$ & $2.390(0.44)$ & $2.042(0.26)$ & $2.001(0.31)$ & $2.049(0.28)$ \\
$\operatorname{lgE}(\mathrm{KU} / \mathrm{l})$ & $31.175(8.73)$ & $34.870(11.36)$ & $32.437(9.59)$ & $34.930(10.24)$ & $34.779(10.12)$ \\
Total $\operatorname{lgG}(\mathrm{g} / \mathrm{l})$ & $10.351(0.89)$ & $11.817(1.01)^{*}$ & $10.892(0.85)$ & $10.413(0.88)$ & $10.579(0.69)$ \\
\hline
\end{tabular}



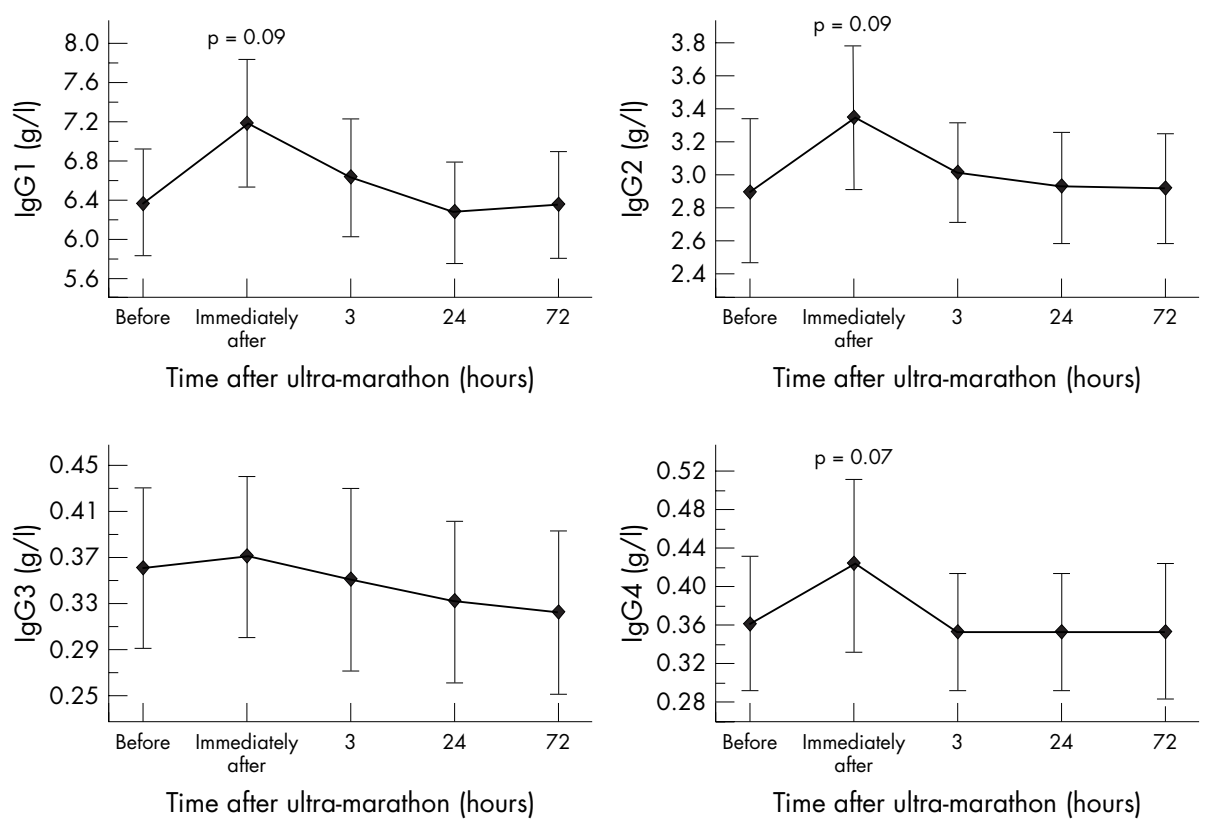

Figure 2 Immunoglobulin $\mathrm{G}(\mathrm{lgG})$ subclass concentrations immediately after the ultra-marathon and up to three days later. Values are mean (SE). $p \leqslant 0.05$, significantly different from the before time point.

One explanation that has been proposed for the increases in certain antibodies after exercise is that non-systemic immunoglobulins are flushed out of secondary lymph "storage" sites and/or enter the circulation because of increased lymphatic flow. ${ }^{14}$ This may have been the reason why IgG returned to baseline concentrations by three hours after exercise, as they then returned to their "storage sites". At present there is no evidence to support such an assumption. ${ }^{14}$ Furthermore, if this had been the case, this would most likely have resulted in significant increases in all systemic antibodies; this did not occur, with certain antibodies showing significant decreases.

We would like to propose that the increase in IgG concentration after the ultra-marathon suggests antibody class switching, similar to that which may occur during a secondary antibody response. This is a process that has only recently been described and involves a switch in immunoglobulin isotype from $\operatorname{IgM}$ to $\operatorname{IgG}^{29}$ This implies that there will be a decrease in measured $\operatorname{IgM}$ as it undergoes genetic rearrangement and is transformed into IgG. ${ }^{29}$ Isotype switching is coordinated by $\mathrm{T}$ helper 2 cytokines ${ }^{4}{ }^{10}$-for example, interleukins 4, 10, and 6-as well as the hypothalamicpituitary-adrenal axis and sympathetic nervous system. ${ }^{30}$ Cortisol (hypothalamic-pituitary-adrenal axis) and noradrenaline (norepinephrine) (sympathetic nervous system) have been shown to promote $\mathrm{B}$ cell immunoglobulin isotype switching from IgM to IgG. ${ }^{30}$ Although the effect of exercise on interleukin 4 has been difficult to detect, interleukin 10, interleukin 6, cortisol, and noradrenaline have been regularly reported to be increased by strenuous endurance exercise. ${ }^{24}$

In this study, IgM was significantly reduced 24 hours $(23 \%)$ after the ultra-marathon. Few studies have reported concentrations of $\operatorname{IgM}$ after ultra-endurance exercise. Nieman et $a l^{1314}$ reported that IgM was increased by $7.2 \%$ one hour into a three hour run at marathon pace, returning to baseline concentrations during the recovery period at 21 hours. Petibois et al ${ }^{16}$ reported a training induced increase in IgM concentration in elite rowers over 12 months. Mashiko $e$ al $^{18}$ found that IgM decreased by $15 \%$ after a 20 day rugby training camp, training two hours a day, six days a week. It is possible that the immunoglobulin response depends on the duration of the event. As in our study, Israel et $a l^{28}$ found that $\operatorname{IgM}$ was decreased by $10 \%$ up to 25 hours after a $75 \mathrm{~km}$ run at high intensity. We would like to suggest two possible explanations for the IgM concentrations detected in our study. Firstly, isotype switching may have occurred as part of a rapid secondary antibody response. Secondly, the decrease may reflect IgM interaction with the innate immune system, specifically complement, in response to exercise induced tissue damage. ${ }^{14}$ Immune complexes formed between $\operatorname{IgM}$ and complement would have been rapidly cleared from the circulation, ${ }^{11}$ reflecting reduced concentrations of IgM in the peripheral blood.

Few reports have investigated the effect of exercise on serum IgD. IgD was significantly decreased immediately after the ultra-marathon and up to 24 hours during recovery, rising to baseline concentration by 72 hours. This was not in agreement with Petibois et $a l^{16}$ who reported that IgD was significantly increased by rowing training over 12 months. The exact function of IgD is still not completely clear. ${ }^{12} 31$ During resting conditions, all naive B cells express IgD on their cell surface. During the early stages of an immunoglobulin response, little IgD antibody is found in the plasma, as the naive $\mathrm{B}$ cells undergo maturation, and isotype switching to IgM or IgG. ${ }^{12}$ Therefore IgD represents a marker of naive $\mathrm{B}$ cells, and its decrease suggests the initiation of an immunoglobulin isotype switch caused by the ultra-marathon.

There is also minimal information available on the effect of exercise on serum IgE, with two studies reporting no significant changes. ${ }^{32} 33$ However, these results are not directly comparable to the present study as the exercise bouts were of a much shorter duration, a $21 \mathrm{~km}$ and $12.8 \mathrm{~km}$ run respectively. $\operatorname{IgE}$ is generally associated with allergic diseases such as asthma and rhinitis, and a role for IgE in the protection against parasites has been proposed. ${ }^{10}$ During isotype switching, IgM may switch to $\operatorname{IgE}$ and this typically occurs in atopic people. ${ }^{10}$ Although the raised concentrations of IgE in the present study (12\%) immediately after the race and 24 and 72 hours later were not significant, it is interesting that there was a large variability in the response, as seen in the large standard error. It is now well recognised that there is a strong genetic component associated with 


\section{What is already known on this topic}

Strenuous exercise is associated with tissue damage, which activates the innate immune system and local inflammation. Interaction between innate and adaptive immunity is essential for maintaining health, suggesting that the adaptive immune system may also be altered by exercise.

$\operatorname{IgE}^{34}$ and this could account in part for the variation observed in our study, although the concentrations were well within the normal laboratory range.

In this study, circulating IgA showed a slight nonsignificant increase immediately after the race, and then returned to baseline concentrations. For the most part, IgA is associated with mucosal secretions in the upper respiratory tract (IgAl) and the gastrointestinal tract (IgA2). ${ }^{35}$ Therefore changes in circulating concentrations were not expected, nor were any dramatic changes noted.

From the immunoglobulin measurements obtained in this study, it is not possible to clearly distinguish the possible source of the IgG antibodies. They may have been the result of an isotype switch of naive B lymphocytes with subsequent immunoglobulins produced by $(a)$ short lived plasma B cells in a primary response, and/or $(b)$ long lived plasma B cells, and/or (c) antigen specific memory $B$ cells, during a secondary or tertiary response. ${ }^{910}$

In general, primary pathogen infection is followed 7-10 days later by a primary immunoglobulin response, comprising predominantly $\operatorname{Ig} M$, with a slight increase in IgG. ${ }^{936}$ Subsequent reinfection with the same pathogen results in a secondary antibody response, with a rapid rise in immunoglobulin concentrations, seen two to five days later, and to a higher peak. ${ }^{9}$ This time the predominant immunoglobulin produced is IgG, with some increase in IgE and IgA, and with the IgM response diminishing or disappearing. ${ }^{36}$ The rapid rise in specific high affinity immunoglobulin is due to their secretion by long lived plasma cells (produced through prior antigen exposure) which can react immediately upon re-exposure to antigen. ${ }^{10}$

Therefore, other than isotype switching, it is possible that long lived plasma cells were responsible for the rapid increase in IgG concentration in this study. Whitham and Blannin ${ }^{37}$ suggested that exercise may enhance and maintain IgG concentrations by increasing the chance of exposure to airborne pathogens because of increased lung ventilation during bouts of exercise. The athletes in this study were all experienced athletes and had participated in the race on an average of four previous occasions. Therefore they had all been exposed to the race environment previously, including the same contaminated air, communal areas such as changing rooms, and race starting line ups. Theoretically, they had all had exposure to similar antigens, which may have resulted in the production and maintenance of long lived plasma B cells specific for antigens encountered during the race. With regard to IgG, the most significant changes were seen immediately after the race and 24 hours later. This rapid response would be more closely associated with a long lived plasma B cell response to antigens encountered during the race, and is therefore reflective of a secondary antibody response. ${ }^{36}$

The limitations of this study are the small number of subjects and the lack of a control group. It has also been suggested that measurement of total immunoglobulin may not be the best means of examining the effects of exercise on immune function and that primary antigen specific, in vivo, immune responses should be used..$^{38}$ Despite these limitations, the study suggests that the serum immunoglobulin
What this study adds

Alterations in immunoglobulin concentrations after an ultraendurance race suggest an enhanced immune response, which may contribute to the maintenance of health after such races.

response observed after an ultra-marathon in seasoned runners represents an enhanced antibody response. Isotype switching or a secondary antibody response may regulate this response. The rapid upregulation of such a response probably afforded protection against pathogens and could help account for the maintenance of the wellbeing of the runners.

\section{Authors' affiliations}

A J McKune, L L Smith, S J Semple, Department of Sport and Physical Rehabilitation Sciences, Tshwane University of Technology, Pretoria, South Africa

A A Wadee, Department of Immunology, University of the

Witwatersrand, Witwatersand, South Africa

Competing interests: none declared

Ethics approval for the study was obtained in May 2002 from the Tshwane University of Technology, Faculty of Health Sciences Ethics Committee.

\section{REFERENCES}

1 Nieman D, Johanssen LM, Lee JW. Infectious episodes in runners before and after the Los Angeles Marathon. J Sportsmed Phys Fitness 1990;30:316-28.

2 Peters EM, Bateman ED. Ultramarathon running and upper respiratory tract infections: an epidemiological study. S Afr Med J 1983;64:582-4.

3 Smith LL. An alternate approach to assessing immune function related to upper respiratory tract infection (URTI). Int SportMed J 2003;4:1-9.

4 Smith LL. Overtraining, excessive exercise, and altered immunity: is this a T helper-1 versus T helper-2 lymphocyte response? Sports Med 2003;33:347-64.

5 Ceddia MA, Woods JA. Exercise suppresses macrophage antigen presentation. J Appl Physiol 1999;87:2253-8

6 Pedersen BK, Ullum H. NK cell response to physical activity: possible mechanisms of action. Med Sci Sports Exerc 1994;26:140-6.

7 Kendall A, Hoffman-Goetz L, Houston M, et al. Exercise and blood lymphocyte subset responses: intensity, duration, and subject fitness effects. J Appl Physiol 1990;69:251-60.

8 Shephard RJ, Rhind S, Shek PN. Exercise and training: influences on cytotoxicity, interleukin-1, interleukin-2 and receptor structures. Int J Sports Med 1994; 15:154-66.

9 Roitt I, Brostoff J, Male D. Immunology, 6th ed. Edinburgh: Mosby, 2001

10 Crotty S, Ahmed R. Immunological memory in humans. Semin Immunol 2004; 16:197-203.

11 Boes $M$. Role of natural and immune $\lg M$ antibodies in immune responses. Mol Immunol 2000;37:1 141-9.

12 Janeway CA, Travers $P$, Walport $M$, et al. Immunobiology: the immune system in health and disease, 5th ed. New York: Garland Publishing, 2001.

13 Nieman DC, Tan SA, Lee JW, et al. Complement and immunoglobulin levels in athletes and sedentary controls. Int J Sports Med 1989;10:124-8.

14 Nieman DC, Nehlsen-Cannarella SL. The effects of acute and chronic exercise and immunoglobulins. Sports Med 1991;11:183-201.

15 Nehlsen-Cannarella SL, Nieman DC, Jessen J, et al. The effects of acute moderate exercise on lymphocyte function and serum immunoglobulin levels. Int J Sports Med 1991;12:391-8.

16 Petibois C, Cazorla G, Deleris G. The biological and metabolic adaptations to 12 months training in elite rowers. Int J Sports Med 2003;24:36-42.

17 Mackinnon LT, Hooper SL. Mucosal (secretory) immune system responses to exercise of varying intensity and during overtraining. Int J Sports Med 1994;15:S179-83.

18 Mashiko T, Umeda T, Nakaji S, et al. Effects of exercise on the physical condition of college rugby players during summer training camp. $\mathrm{Br} J$ Sports Med 2004;38:186-90.

19 Ross WD, Wilson NC. Growth and development. A stratagem for propotional growth assessment. Acta Paediatr Belg 1974;24:169-82.

20 Mars M, Govender S, Weston A, et al. High intensity exercise: a cause of lymphocyte apoptosis? Biochem Biophys Res Commun 1998;249:366-70.

21 Powers SK, Howley ET. Exercise physiology: theory and application to fitness and performance, 4th ed. New York: McGraw-Hill Higher Education, 2001.

22 Peters EM, Goetzsche JM, Grobbelaar B, et al. Vitamin C supplementation reduces the incidence of postrace symptoms of upper-respiratory-tract infection in ultramarathon runners. Am J Clin Nutr 1993;57:170-4.

23 Dill DB, Costill DL. Calculation of percentage changes of blood, plasma and red cells in dehydration. J App Physiol 1974;37:247-8. 
24 Mackinnon LT. Advances in exercise immunology. Torrens Park, South Australia: Human Kinetics, 1999.

25 Ohlin $M$, Zouali $M$. The human antibody repertoire to infectious agents implications for disease pathogenesis. Mol Immunol 2003;40:1-11.

26 Poortmans JR. Serum protein determination during short exhaustive physical activity. J Appl Physiol 1971;30:190-2.

27 Poortmans JR, Haralambie G. Biochemical changes in a $100 \mathrm{~km}$ run: proteins in serum and urine. Eur J Physiol 1979;40:245-54.

28 Israel S, Buhl B, Neumann G. Die konzentration der immunglobuline A, G und $M$ im serum bei trainierten und untrainierten sowie nach verschiedenen sportlicken ausdauerleistungen. Med Sport (Berlin) 1982;22:225-31.

29 Coffman RL, Lebman DA, Rothman P. Mechanism and regulation of immunoglobulin isotype switching. Adv Immunol 1993;54:229-70.

30 Elenkov IJ, Wilder RL, Chrousos GP, et al. The sympathetic nerve: an integrative interface between two supersystems: the brain and the immune system. Pharmacol Rev 2000;52:595-638.

31 Roitt I. Essential immunology, 8th ed. Oxford: Blackwell Science, 1994.
32 Hanson PG, Flaherty DK. Immunological responses to training in conditioned runners. Clin Sci 1981;60:225-8.

33 Gmûnder FK, Joller PW, Joller-Jemelka HI, et al. Effect of a herbal yeast food supplement and long-distance running on immunological parameters. BrJ Sports Med 1990;24:103-12.

34 Romagnani S. The Th1/Th2 paradigm and allergic disorders. Allergy 1998;53(suppl 46):12-15.

35 Gleeson M. Mucosal immunity and respiratory illness in elite athletes. Int J Sports Med 2000;21 (suppl 1):S33-43.

36 Stavnezer J. Immunlglobulin class switching. Curr Opin Immunol 1996;8:199-205.

37 Whitham M, Blannin AK. The effect of exercise training on the kinetics of the antibody response to influenza vaccination. J Sports Sci 2003;21:991-1000.

38 Smith TP, Kennedy SL, Fleshner M. Influence of age and physical activity on the primary in vivo antibody and T cell-mediated responses in men. J Appl Physiol 2004;97:491-8.

\section{Call for papers}

11 th European Forum on Quality Improvement in Health Care 26-28 April 2006, Prague, Czech Republic

Deadline 30 September 2005.

For further information and to submit online go to: www.quality.bmipg.com 